\title{
Loss of independence in Katz's ADL ability in connection with an acute hospitalization: early clinical markers in French older people
}

\author{
Pierre-Olivier Lang · Nicolas Meyer · Damien Heitz · Moustapha Dramé • Nicolas Jovenin · \\ Joël Ankri · Dominique Somme · Jean-Luc Novella · Jean-Bernard Gauvain • \\ Pascal Couturier · Isabelle Lanièce · Thierry Voisin · Benoit de Wazières • \\ Régis Gonthier · Claude Jeandel · Damien Jolly · Olivier Saint-Jean · François Blanchard
}

Received: 3 April 2007/ Accepted: 29 May 2007/Published online: 25 July 2007

(C) Springer Science+Business Media B.V. 2007

\begin{abstract}
Background The preservation of autonomy and the ability of elderly to carry out the basic activities of daily living, beyond the therapeutic care of any pathologies, appears as one of the main objectives of care during hospitalization. Objectives To identify early clinical markers associated with the loss of independence in elderly people in short stay hospitals.
\end{abstract}

P.-O. Lang $(\bowtie) \cdot$ P. Couturier · I. Lanièce

T. Voisin · B. de Wazières · R. Gonthier .

C. Jeandel

Department of Rehabilitation and Geriatrics, Hospital of TroisChêne, University Hospitals of Geneva, Chemin du Pont-Bochet 3, Thônex-Genève, 1226 Geneva, Switzerland

e-mail: Pierre.O.Lang@hcuge.ch

P.-O. Lang · M. Dramé · N. Jovenin · D. Somme ·

J.-L. Novella · D. Jolly · F. Blanchard

University of Reims Champagne-Ardenne, School of Médecine,

E.A.3797 Reims, France

\section{N. Meyer}

Department of Public Health, University Hospitals of

Strasbourg, Strasbourg, France

\section{Heitz}

Department of Geriatrics, University Hospitals of Strasbourg, Strasbourg, France

M. Dramé · J.-L. Novella · F. Blanchard

Department of Gerontology, University Hospitals of Reims, Reims, France

N. Jovenin · D. Jolly

Clinical Research Unit, University Hospitals of Reims, Reims, France

\section{J. Ankri}

Center of Gerontology, Hospital Sainte Perrine, Assistance

Publique Hôpitaux de Paris, Paris, France
Methods Among the 1,306 subjects making up the prospective and multicenter SAFEs cohort study (Sujet Agé Fragile: Évolution et suivi-Frail elderly subjects, evaluation and follow-up), 619 medical inpatients, not disabled at baseline and hospitalized through an emergency department were considered. Data used in a multinomial logistic regression were obtained through a comprehensive geriatric assessment (CGA) conducted in the first week of

\section{Somme - O. Saint-Jean}

Geriatrics Unit, European Hospital Georges Pompidou,

Assistance Publique Hôpitaux de Paris, Paris, France

\section{J.-B. Gauvain}

Center of Geriatrics Medicine, Hospital Porte Madeleine,

General Hospital Center of Orleans, Orleans, France

\section{P. Couturier · I. Lanièce}

Geriatrics Clinic, University Hospitals of Grenoble, Grenoble, France

\section{T. Voisin}

Geriatrics and Gerontology Center, University Hospitals of

Toulouse, Toulouse, France

B. de Wazières

Geriatrics unit, University Hospitals of Nimes, Nimes, France

R. Gonthier

Clinical gerontology unit, University Hospital of Saint Etienne,

Saint Etienne, France

C. Jeandel

Center of clinical gerontology, University Hospitals of Montpellier, Montpellier, France 
hospitalization. Dependency levels were assessed at baseline, at inclusion and at 30 days using Katz's ADL index. Baseline was defined as the dependence level before occurrence of the event motivating hospitalization. To limit the influence of rehabilitation on the level of dependence, only stays shorter than 30 days were considered.

Results About 514 patients were eligible, 15 died and 90 were still hospitalized at end point $(n=619)$. Two-thirds of subjects were women, with a mean age of 83 . At day 30 162 patients (31\%) were not disabled; 61 (12\%) were moderately disabled and 291 severely disabled (57\%). No socio-demographic variables seemed to influence the day 30 dependence level. Lack of autonomy (odds ratio $(\mathrm{OR})=1.9,95 \%$ confidence interval $(\mathrm{CI})=1.2-3.6)$, walking difficulties $(\mathrm{OR}=2.7,95 \% \mathrm{CI}=1.3-5.6)$, fall risk $(\mathrm{OR}=2.1,95 \% \mathrm{CI}=1.3-6.8)$ and malnutrition risk $(\mathrm{OR}=2.2,95 \% \mathrm{CI}=1.5-7.6)$ were found in multifactorial analysis to be clinical markers for loss of independence.

Conclusions Beyond considerations on the designing of preventive policies targeting the populations at risk that have been identified here, the identification of functional factors (lack of autonomy, walking difficulties, risk of falling) suggests above all that consideration needs to be given to the organization per se of the French geriatric hospital care system, and in particular to the relevance of maintaining sector-type segregation between wards for care of acute care and those involved in rehabilitation

Keywords Loss of independence - Katz's ADL abilities · Frail elderly people $\cdot$ SAFEs cohort

\section{Introduction}

Performing the activities of daily life, alone or with the help of another person, appears as the essential element in preserving a person's autonomy, and in enabling independent living of satisfactory quality [1]. These activities, referred to as Activities of Daily Living (ADL), are explored by a measure developed by Katz [2]. This measure, considered to be the best suited to assess levels of dependency in elderly people [3], explores six main dimensions of daily living: bathing, dressing, using the toilet, movement inside the home, feeding and continence.

Hospitalization following the occurrence of an acute pathology, notwithstanding treatment, puts elderly people at risk for functional deterioration, physical and/or mental [4-11]. This deterioration paves the way to loss of autonomy, and generally involves a burden for those close to the subject, recourse to professional helpers and admission to an institution [12-13]. Indeed, studies on living conditions of dependent elderly people living at home in France have noted high levels of solidarity of families and persons close in maintaining dependent senior members of the community in their homes [14].

The different authors that have explored the issues of loss of independence among elderly people have all reached the same conclusion: the preservation of autonomy and the ability of these persons to carry out the basic ADL, beyond the therapeutic care of any pathologies, appears as one of the main objectives of care during hospitalization [4-6, 8, 10, 12]. Among the set of factors identified by these researchers as being associated with loss of independence, the age of subjects has for a long time been considered as preponderant $[5,6,8,10]$. In fact, the dynamic and complex process of deterioration in the ability to perform ADL subsequent to hospitalization, the effect of age per se does not appear to be as direct as has been suggested. Covinsky et al. have indeed shown that age is not an independent explicative factor for functional decline, but rather a factor that is associated with a decrease in potential for recovery [12].

Thus, in a perspective of prevention of loss of independence among elderly hospitalized subjects, we considered it worthwhile attempting, using simple clinical markers, to identify a population at risk for loss of independence. A cohort study, referred to by the acronym SAFEs (Sujet Âgé Fragile: Évolution et suivi-Frail elderly subjects, evaluation and follow-up) provided the opportunity to identify these factors [4]. The subjects included in this survey were hospitalized through Emergency Department (ED). Among the 1,306 subjects making up the SAFEs cohort only those subjects that were independent at baseline in performing Katz ALD were taken into consideration in the present work, this being assessed retrospectively on inclusion in the cohort $[4,12,15]$. Following this and in a prospective manner, dependence was assessed 30 days after admission date to ED.

Candidates for early markers were generated using the Comprehensive Geriatric Assessment (CGA) conducted by a geriatrician in the first week of hospitalization [3]. The endpoint at day 30 was chosen specifically to restrict any influence on the level of dependency of rehabilitation care prolonging the hospital stay [4]. The multi-centre SAFEs cohort study stems from a Clinical Research Hospital Programme, the object of which was to improve early screening, to determine the factors affecting the evolution of health status, and to define procedures for the care of frail elderly patients [4].

\section{Materials and methods}

Study population

The study design, cohort sampling procedures, and inclusion and non-inclusion criteria of the SAFEs study 
have already been described in a recent publication [4]. Of the 1,306 subjects included in the SAFEs cohort study, only patients independent at baseline were considered in the present study. Subjects were described as "not disabled" if they were independent at baseline for ADL. The flow of participants through the study is summarized in Fig. 1. For ethical aspects, informed consent was signed by each willing subject or by a representative. Patients were free to refuse to take part in the study or to withdraw from it at any stage on simple request, without any alteration to care provided, in observance of French law relating to the protection of individuals participating in medical research. The Reims (France) Ethical Committee issued agreement for the conduct of the survey.

\section{Geriatric assessment}

A geriatrician, assisted by a member of the healthcare team, the principle caregiver, or both, evaluated each patient included. This evaluation gathered a large quantity of clinical and socio-demographic data concerning patients and the quality of life of their caregivers where there was one. Validated assessment instruments were used. Dependency levels for ADL at baseline, at inclusion and at day 30 among discharged patients were assessed using the Katz ADL index [2]. Baseline ADL performance was defined as the dependence level of the subject before occurrence of the event motivating hospitalization (performance in ADL 2 weeks before admission) [12].

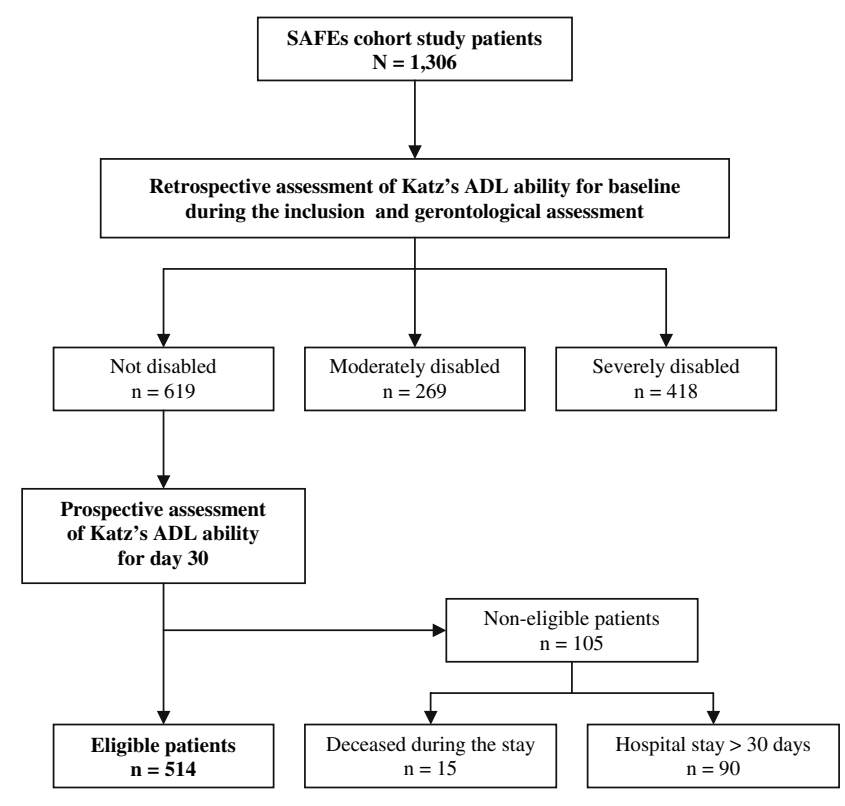

Fig. 1 Participant enrolment, attrition, and follow-up
Five items from the Katz ADL index - bathing, dressing, toilet use, transfer and feeding - were used to construct a three-level, five-item ADL scale (continence was not included, in accordance with the recommendations in the literature [16]).

Each item was scored 0 or $1(0=$ able to perform the activity without any help; $1=$ able to perform the activity with little or complete help). The scoring system gave a score range from 0 to 5 . Absence of disability ("not disabled"-ADL score $=0$ ) was defined as being independent for all items, "moderately disabled" (ADL score 1-2) as dependent for one or two items, and "severely disabled" (ADL score > 2) as dependent for three or more items. These scores defined three main groups, which ranged from a group capable of performing basic activities independently to a group that was dependent in the majority of the five basic activities [15]. Mood and depression risk were assessed using Schwab and Gilleard's Depression Scale (score ranges: 40-10) [17, 18]. A mood disorder was defined as a score greater than 14. The Folstein Mini-Mental State Examination was used for the assessment of cognitive functions (MMSE score ranges 30-0). A score of less than 25 defined a cognitive impairment, whatever the etiology [19]. A risk of malnutrition was defined as a Mini Nutritional Assessment short Form score of less than 12 (MNAsf score ranges 14-0) [20]. Walking and balance difficulties were estimated using the Timed Get Up and Go Test and the one-leg-balance test, respectively [21, 22]. A patient requiring more than $20 \mathrm{~s}$ to complete the Timed Get-up and Go Test was considered to have walking difficulties. If a patient was unable to stand on either $5 \mathrm{~s}$ leg at least, s/he was considered to have difficulties balancing when standing. A modified version of the Charlson index (applicable to pathologies coded in CIM 10) made it possible to establish three levels of severity for co-morbidity: mild co-morbidity (Charlson index $<2$ ), moderate co-morbidity $(2 \leq$ Charlson index between $\leq 4)$ and severe co-morbidity (Charlson index $\geq 5$ ). These thresholds have already been used by other authors [23, 24]. The risk of developing pressure ulcers was assessed using the Norton scale (score ranges: 20-5): a score of 14 or less indicated risk of developing decubitus ulcers [25]. Duke's Health Profile was used to investigate patients' quality of life through physical, psychological, and social functioning. Each of the 10 dimensions explored is presented in the form of a normalized scale: 0 (worst quality of life) to 100 (best possible) [26]. Caregiver burden was assessed using the Zarit Burden Inventory (score ranges: 0-88; categories: no or low burden -0 to 20 , low to moderate burden -21 to 40 , moderate to high burden -41 to 60 , higher burden -61 to 88) [27]. Following this CGA, a clinical profile for each patient was developed according to the clinical opinion of the geriatrician. This profile is presented in the form of 15 
geriatric syndromes (Table 1) [4]. The departments of Medical Records and Clinical Epidemiology provided administrative data concerning the hospital stays. The length of stay was defined as the interval between admission date and discharge date from a one and the same hospital.
Table 1 Inclusion characteristics of "not disabled" Sujet Âgé Fragile: Évaluation et suivi Cohort Patients for baseline
${ }^{\mathrm{a}} P<0.05$ indicates a difference according to the dependence level

$\mathrm{SD}=$ standard deviation

$\mathrm{ADL}=$ Activities of daily living

Charlson's CI $=$ Charlson

Comorbidity Index

LoS = Length of Stay

\begin{tabular}{|c|c|c|c|c|c|}
\hline \multirow[t]{2}{*}{ Characteristic } & \multirow[t]{2}{*}{ All $(N=514)$} & \multicolumn{3}{|c|}{ 30th day Katz's ADL } & \multirow[t]{2}{*}{$P$-value ${ }^{\text {a }}$} \\
\hline & & $\begin{array}{l}\text { Not } \\
\text { disabled } \\
(n=162)\end{array}$ & $\begin{array}{l}\text { Moderately } \\
\text { disabled } \\
(n=61)\end{array}$ & $\begin{array}{l}\text { Severely } \\
\text { disabled } \\
(n=291)\end{array}$ & \\
\hline \multicolumn{6}{|l|}{ Demographic } \\
\hline Age, mean \pm SD & $82.8 \pm 5.3$ & $81.9 \pm 5.6$ & $81.6 \pm 5.0$ & $84.1 \pm 5.1$ & 0.04 \\
\hline Gender, $\%$ & & & & & 0.6 \\
\hline Women & 60.3 & 58.9 & 63.2 & 60.5 & \\
\hline Men & 39.7 & 41.1 & 36.8 & 39.5 & \\
\hline Living condition, $\%$ & & & & & 0.7 \\
\hline Private home & 86.7 & 86.1 & 89.5 & 86.4 & \\
\hline Institution & 13.3 & 13.9 & 10.5 & 13.6 & \\
\hline Marital status, $\%$ & & & & & 0.4 \\
\hline Single & 8.6 & 10.7 & 10.5 & 7.0 & \\
\hline Married & 35.6 & 28.7 & 31.6 & 40.4 & \\
\hline Divorced & 4.6 & 4.7 & 8.8 & 3.7 & \\
\hline Widowed & 51.2 & 56.0 & 49.1 & 48.9 & \\
\hline Caregiver, $\%$ & 57.4 & 41.1 & 42.1 & 43.6 & 0.8 \\
\hline Inclusion Katz's ADL, \% & & & & & 0.7 \\
\hline Not disabled & 28.6 & 29.8 & 22.8 & 29.1 & \\
\hline Moderately disabled & 19.8 & 17.2 & 21.1 & 21.0 & \\
\hline Severely disabled & 51.6 & 53.0 & 51.1 & 49.9 & \\
\hline Charlson's CI, \% & & & & & 0.04 \\
\hline Low & 69.3 & 73.5 & 73.7 & 66.4 & \\
\hline Medium & 27.8 & 26.5 & 24.6 & 28.8 & \\
\hline High & 2.9 & 0.0 & 1.7 & 4.8 & \\
\hline \multicolumn{6}{|c|}{ Fifteen geriatric syndrome classification } \\
\hline Lack of autonomy, $\%$ & 56.4 & 483 & 43.8 & 63.5 & 0.03 \\
\hline Poor overall condition, $\%$ & 33.5 & 32.5 & 31.6 & 33.0 & 0.3 \\
\hline Cognitive impairment, $\%$ & 20.0 & 22.5 & 19.3 & 18.8 & 0.6 \\
\hline Delirium, \% & 11.6 & 12.2 & 12.3 & 11.2 & 0.9 \\
\hline Mood disorders, $\%$ & 75.2 & 74.0 & 77.2 & 75.5 & 0.9 \\
\hline Failure to thrive syndrome & 2.7 & 3.3 & 1.8 & 2.6 & 0.8 \\
\hline Postfall syndrome, $\%$ & 3.6 & 2.0 & 5.3 & 4.1 & 0.4 \\
\hline Bedridden, $\%$ & 5.5 & 4.7 & 7.0 & 5.6 & 0.6 \\
\hline Walking difficulties, $\%$ & 71.5 & 67.5 & 68.4 & 77.1 & 0.05 \\
\hline Risk of fall & 43.0 & 34.4 & 33.3 & 49.8 & 0.03 \\
\hline Risk of malnutrition & 59.9 & 51.6 & 50.9 & 66.4 & 0.04 \\
\hline Pressure sores & 2.1 & 2.0 & 1.8 & 2.2 & 0.9 \\
\hline Sight disorders & 38.2 & 36.7 & 26.3 & 41.5 & 0.07 \\
\hline Deafness & 34.6 & 37.3 & 38.6 & 32.3 & 0.5 \\
\hline Incontinence & 22.1 & 24.7 & 21.1 & 20.8 & 0.6 \\
\hline \multicolumn{6}{|l|}{ Hospital stay } \\
\hline LoS (day; mean \pm SD) & $13.0 \pm 6.54$ & $12.8 \pm 6.6$ & $13.3 \pm 6.2$ & $13.0 \pm 6.6$ & 0.7 \\
\hline Acute Care for Elderly unit, \% & 23.6 & 25.2 & 21.1 & 23.3 & 0.8 \\
\hline Multiunit stay, $\%$ & 6.1 & 3.9 & 3.5 & 7.7 & 0.01 \\
\hline
\end{tabular}


Statistical analysis

A descriptive analysis of the administrative, sociodemographic, and clinical variables of the patients was performed. Descriptive results concerning numerical variables are presented in the form of means, SD, and median for Mean Length of Stay (MLoS). For categorical variables, sample sizes and percentages calculated are presented. Patient characteristics at inclusion were compared with respect to their dependency level at day 30. The tests used were chosen according to the type of variable and the sample size under consideration. Categorical variables were tested using chi-square $\left(\chi^{2}\right)$ or Fisher exact tests; variance analysis and Kruskall-Wallis tests were used for numerical variables [28]. The unifactorial analysis results identified the variables associated with loss independence one month after ED admission. The selection threshold for the useful variables in multifactorial analysis was set at $P=0.30$. All the variables thus selected were introduced into a multinomial logistic regression multifactorial model. This considers the effect of each factor after adjustment for all the other factors with a judgement criterion in the form of a variable with more than two response levels (not disabled-moderately disabled-severely disabled) [29].

The results of this multifactorial analysis were presented in the form of odds ratios (ORs) with $95 \%$ confidence intervals (CIs). For the OR calculation, the chosen reference level of the judgement criterion was systematically "not disabled". Thus, for each candidate variable two $\mathrm{ORs}$ were generated: $\mathrm{OR}_{1}$-moderately disabled versus not disabled; $\mathrm{OR}_{2}$ - severely disabled versus not disabled. "Age", "gender", "centre" and DRG (Diagnostic Related Group) variables were forced into the model. The effects of the other variables were systematically adjusted for these four factors. Interaction variables, associating the center and the different descriptive variables, were also tested in both analysis models. Multifactorial analyses were computed with the PROC CATMOD for SAS ${ }^{\circledR}$ software (SAS System, SAS Institute Inc., Carry, North Carolina). A backward elimination procedure with authorized re-entry was used to select the final model. To construct the initial model, all variables with $P=0.30$ in unifactorial analysis were candidates. In the backward elimination procedure, the variables were removed one by one, with an exit threshold set at $P=0.10$. The level of significance was set at $P=0.05$. To analyze possible multicollinearity between variables selected using multifactorial analysis, Spearman correlation coefficients $(r)$ were calculated [28]. Statistical analyses were performed using SAS $^{\circledR}$ software, version 8.2 .

\section{Results}

Of the 1,306 subjects included in the evaluation conducted by the geriatrician between the 4 th and the 7 th day of hospitalization, 619 patients were considered as not disabled at baseline according to Katz's ADL index. At day 30 assessment, 15 patients had died and 90 were still hospitalized (Fig. 1). The geriatric assessment data for these patients was compared with that for the 514 other 30-day discharge subjects. No statistically significant difference was found (Fisher's exact test: $P>0.05$ ). Therefore, the exclusion of the 105 non-eligible subjects from the analysis did not create any significant selection bias. The analysis thus covers 514 inpatients at nine French hospitals. Assessments of dependency level according to Katz's ADL index, at inclusion and 30 days after emergency hospitalization, showed that $71 \%$ of the patients were dependent for at least one ADL at inclusion and nearly $69 \%$ were still dependent at day 30 and more than $80 \%$ of these for three or more ADL (Table 1).

The sociodemographic data of subjects and the descriptive data of the hospital stays are presented in Table 1. Two thirds of the cohort were women $(60 \%)$. The average age $\pm \mathrm{SD}$ of the sample was $83 \pm 5.3$ (range 75-101). Fifty-seven percent of subjects reported that they had a caregiver. The gender of the subjects and the presence of a caregiver had no influence on the loss of independence (Fisher's exact test: $P>0.05$ ) in unifactorial analysis. The oldest subjects were more often disabled than others at day 30 assessment (ANOVA: $P=0.04$ ).

The 514 stays analyzed amounted to 6,227 hospitalization days, covering 90 DRGs (Neurology: 44\%; Cardiology: 13\%). The MLoS was $13 \pm 6.5$ days. Half the discharges took place between the 7 th and 14th day. One hundred and twenty-one patients were hospitalized in an ACE unit $(23 \%)$. Six percent of all stays were multiunit stays $(n=31)$. This type of stay tends to foster loss of independence 30 days after an emergency admission (not disabled: 3.9\%-moderately disabled: 3.5\%-severely disabled: 7.7\%; Fisher's exact test: $P=0.01$ ). The MLoS of these stay types was not different from that for the single-unit stays (Kruskall \& Wallis's test: $P>0.05$ ). This factor was not considered in the multifactorial analysis model, since this variable, which was only known at the end of the stay, could not be considered in the predictive approach.

The 15-syndrome geriatric classification is presented in Table 1 . Nearly $60 \%$ of the cohort presented lack of autonomy, more than $80 \%$ presented walking difficulties, and more than $40 \%$ had a risk of falling. The cognitive status of $20 \%$ of subjects was impaired, $11 \%$ were delirious, and $75 \%$ presented a mood disorder. Five percent were bedridden, and nearly half of these $(2 \%)$ presented one or 
more pressure sores. According to the MNA-sf data, the nutritional evaluation estimated that $60 \%$ of the patients were at risk for malnutrition on admission. In unifactorial analysis, the following had an influence on the dependency level at day 30 (Fisher's exact test: $P<0.05$ ): the comorbidity level according to the Charlson's $\mathrm{CI}$, a diagnosis at inclusion of lack of autonomy, walking difficulties, risk of falls or risk of malnutrition. On the other hand, the dependency level observed at inclusion was not identified as an early clinical marker for loss of independence (Table 1).

Multicollinearity analysis showed that all other Spearman $\mathrm{r}$ coefficients calculated between variables with a $P$ value $\leq 0.3$ in unifactorial analysis also yielded $\leq 0.3$. These values reflect low levels of multicollinearity between variables selected in the multifactorial analysis.

The ORs, calculated using multinomial logistic regression model, as an estimation of the association between the descriptive variables generated by the geriatric evaluation and the loss of independence according to Katz's ADL assessment at day 30 are presented in Table 2. The results presented in the table involve only the variables used to construct the final model. Sociodemographic data and all interaction-variable $P$-values were higher than the exit threshold (Wald's test: $P>0.10$ ). Multifactorial analysis reveals clinical markers, notably functional and nutritional (Wald's test: $P<0.05$ ). These are: "lack of autonomy" $\left(\mathrm{OR}_{1}=1.4 \quad[0.9-2.2] ; \quad \mathrm{OR}_{2}=1.9 \quad[1.2-3.6]\right)$; "walking difficulties" $\left(\mathrm{OR}_{1}=1.8[1.1-2.8] ; \mathrm{OR}_{2}=2.7\right.$ [1.3-5.6]); an unsuccessful one-leg balance test defining the "risk of fall" $\left(\mathrm{OR}_{1}=1.6[1.0-2.3] ; \mathrm{OR}_{2}=2.1[1.3-6.8]\right)$ and "risk of malnutrition" according to the MNA-sf assessment $\left(\mathrm{OR}_{1}=1.7\right.$ [0.9-2.3]; $\mathrm{OR}_{2}=2.2$ [1.5-7.6] $)$ all of which were associated with the loss of independence in discharged outpatients 30 days after hospitalization for an acute condition.

\section{Discussion}

This prospective study concerning 514 patients who were independent at baseline and hospitalized in emergency has shown that nearly $60 \%$ of subjects had become dependent one month after admission for the performance of at least 3 of the 5 ADL under consideration. This work has made it possible to pinpoint simple clinical factors that can be considered to be early indicators of loss of independence, since they are identifiable at the time of admission. Thus a diagnosis of "lack of autonomy", "walking difficulties", "fall risk" and "malnutrition risk" derived from a comprehensive geriatric assessment (CGA) conducted in the first week of hospitalization were associated with loss of independence one month after admission. Neither the socio-demographic variables nor the level of dependence observed on admission were found to be associated.

The CGA conducted in the first week of hospitalization by a geriatrician provides precise information about living conditions, social and domestic environment and health status of the patient. In this assessment functional and cognitive abilities, mood and nutritional status and quality of life are explored using standardized measures [3]. This evaluation constitutes a medical approach to the elderly subject, which has proved its efficiency [30]. Once combined with the clinical experience of the geriatrician, it provides a clinical description of the subject in the form of 15 "geriatric syndromes" [4]. In the course of the CGA, the level of dependency is assessed by the Katz ADL index [2]. This instrument is considered as the best suited to assessing overall dependency levels, via exploration of six areas of daily living: bathing, dressing, use of the toilet, movement around the home, feeding and continence. The method for calculating a global score using only 5 of these 6 ADL follows recommendations in the literature for reasons of interobserver reproducibility [16], and the three-level scale for dependency based on these items has been validated in the literature [15].

With regard to the socio-demographic data for the patients studied, results show absence of any predictive value of this data for levels of dependency at one month. Except for age, the significance index associated with these variables in unifactorial analysis was above the selection threshold chosen $(P=0.30)$.

In addition, after adjustment on all the candidate variables, the associations observed in unifactorial analysis between age and loss of independence disappeared. Covinsky et al. have shown that the frequency of deterioration in dependency levels between baseline and discharge from hospital varies significantly with age (respectively 23 , $28,38,50$ and $63 \%$ of subjects aged 70-74, 75-79, 80-84, $85-98$ and $\geq 90, P<0.001)$. However, after adjustment on potential confounders, age in the present study was no longer found to be associated with functional decline as measured by the Katz ADL index [12]. The age at admission is therefore not an independent factor for loss of independence following hospitalization for an acute condition.

The indicators for loss of independence identifiable at the start of hospitalization are clinical indicators. Lack of autonomy $(\mathrm{OR}=1.9)$; walking difficulties $(\mathrm{OR}=2.7)$; fall risk $(\mathrm{OR}=2.1)$ and malnutrition risk $(\mathrm{OR}=2.2)$ are the risk indicators identified for loss of independence following emergency hospitalization.

Autonomy is, as in the definition proposed by Beauchamp et al., the ability of an individual to be self-sufficient [31]. It assumes faculties of judgement, i.e., the 
Table 2 Multifactor and multinomial logistic regression analysis of predictive factors for loss independence 30 days after hospitalization for acute condition $(N=514)$

\begin{tabular}{|c|c|c|c|c|c|c|c|}
\hline \multirow{4}{*}{$\begin{array}{l}\text { Characteristic } \\
\text { Charlson's CI }\end{array}$} & \multicolumn{6}{|c|}{ Associated factors of loss of independence } & \multirow[t]{3}{*}{$P$-value } \\
\hline & \multirow{2}{*}{\multicolumn{2}{|c|}{$\frac{\text { Not disabled }}{\mathrm{OR}^{\mathrm{a}}(95 \% \mathrm{CI})}$}} & \multicolumn{2}{|c|}{ Moderately disabled } & \multicolumn{2}{|c|}{ Severely disabled } & \\
\hline & & & & & & & \\
\hline & & & & & & & 0.07 \\
\hline Low & 1 & - & 1 & - & 1 & - & \\
\hline Medium & 1 & - & 1.1 & $(0.6-1.9)$ & 1.4 & $(0.9-7.6)$ & \\
\hline High & 1 & - & 1.2 & $(0.6-1.9)$ & 1.9 & $(0.9-8.8)$ & \\
\hline Lack of autonomy & & & & & & & 0.04 \\
\hline No & 1 & - & 1 & - & 1 & - & \\
\hline Yes & 1 & - & 1.4 & $(0.9-2.2)$ & 1.9 & $(1.2-3.6)$ & \\
\hline Poor overall condition & & & & & & & 0.1 \\
\hline No & 1 & - & 1 & - & 1 & - & \\
\hline Yes & 1 & - & 1.1 & $(0.6-2.5)$ & 1.2 & $(0.8-2.7)$ & \\
\hline Walking difficulties & & & & & & & 0.03 \\
\hline No & 1 & - & 1 & - & 1 & - & \\
\hline Yes & 1 & - & 1.8 & $(1.1-2.8)$ & 2.7 & $(1.3-5.6)$ & \\
\hline Risk of fall & & & & & & & 0.04 \\
\hline No & 1 & - & 1 & - & 1 & - & \\
\hline Yes & 1 & - & 1.6 & $(1.0-2.3)$ & 2.1 & $(1.3-6.8)$ & \\
\hline Risk of malnutrition & & & & & & & 0.03 \\
\hline No & 1 & - & 1 & - & 1 & - & \\
\hline Yes & 1 & - & 1.7 & $(0.9-2.3)$ & 2.2 & $(1.5-7.6)$ & \\
\hline Sight disorders & & & & & & & 0.09 \\
\hline No & 1 & - & 1 & - & 1 & - & \\
\hline Yes & 1 & - & 0.9 & $(0.6-1.5)$ & 1.00 & $(0.7-2.3)$ & \\
\hline
\end{tabular}

${ }^{a}$ Odds ratio $(\mathrm{OR})>1$ indicates a factor related to a loss of independence. The link is significant if the value 1 is not within the $95 \%$ confidence interval $(\mathrm{CI})$

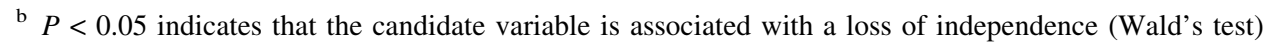

Charlson's CI = Charlson Comorbidity Index

ability to foresee and choose freedom to act, accept or refuse according to judgement. Thus autonomy relates at once to ability [31]. Although the term autonomy is increasingly encountered in the literature, there is often a confusion between loss or lack of autonomy and dependency. Dependency is an over-simplification of the notion of lack of autonomy [32]. In this study, the diagnosis of lack of autonomy was made according to the clinical opinion of the geriatrician, since no standardized instrument has been developed. The measures at present available explore people's autonomy within the sphere of medical care and therapeutic provision [32].

Although this factor is significantly associated with the loss of independence $(P=0.04)$ there may be a classification bias on account of the subjectivity of the concept as assessed by a clinician. This bias is difficult to estimate after the fact, so that the association observed needs to be taken with caution.
Walking difficulties and fall risk have already been described by other authors as predictive factors for loss of independence in the performance of $\operatorname{ADL}[13,33]$. The period in bed subsequent to an acute pathology often aggravates walking difficulties, and thereby increases risk of falling. Rehabilitation care aiming to return to the previous functional level is only rarely provided in short stay wards. Thus the lack of downstream rehabilitation facilities and follow-up care is one of the explicative factors for the association observed between functional disorders and the level of dependency at the end of hospitalization [34].

Walking difficulties are not the only factor for risk of falling as confirmed by the association between fall risk and loss of independence after adjustment on walking difficulties. Neurological, neuro-muscular, osteo-articular and medication-related factors are associated with the risk of falling [35, 36]. Numerous pathologies can affect adaptation to effort and compensatory postural movements. 
Protein and calorie-deficient dietary intake, via its effect on muscular strength, and on peripheral and central neurological functions, can make falls more likely [4, 37]. Falls can have a psychological effect, and lead to the need for more specialized rehabilitation and psychological care, delaying functional recovery $[4,38]$.

A risk of malnutrition on admission as detected by the MNA-sf was also identified as an early indicator of loss of independence subsequent to emergency hospitalization. The functional morbidity consecutive to under-nutrition is probably an explicative factor of this association [39]. Protein-calorie malnutrition, frequent in the elderly, leads to muscular loss, and the functional consequences of this are particularly damaging [40]. In the course of a hospital stay, fasting in connection with the performance of certain examinations, the sometimes inadequate help with feeding and/or the anorexic effect of certain types of medication will lead to a reduction in protein and calorie intake [37, 41]. Asthenia and anorexia that follow on from pathological situations, and increased metabolic requirements related to chronic inflammatory states, increase the body's energy consumption [37]. To compensate, the body will draw on reserves found in muscle, already small at the time of admission, thus resulting in loss of muscular strength $[37,41]$.

The mainly functional clinical factors associated with loss of independence highlighted in this study should suggest reconsideration of the organization of the care offer in classic hospitalization facilities, and in particular of the place of acute geriatric care, and the development of follow-up and rehabilitation care provision [34, 42]. This adaptation of the care offer is all the more necessary in France because the proportion of elderly subjects in hospitalized populations is constantly increasing [43], and the instatement of the "T2A" ruling (activity-related charges) will lead to a calculated reduction in duration of hospital stays for reasons of economic viability [44, 45]. Indeed, the T2A ruling is the new European funding mode. The method is based on a link between the volume and the nature of the care provision activity and the resources allocated for the functioning of the health facility [4]. A funding rate is determined for each type of activity. At the end of each hospital stay each patient is classified in a homogeneous DGR group according to the type of stay (f-DRG in the French classification) corresponding to a national reimbursement rate, which is partly dependent upon the length of stay. A span of stay duration (with floor and ceiling cut-off values) is associated with each f-DGR. If the duration of hospitalization falls outside this range, a coefficient of 0.75 instead of 1 is applied for the reimbursement of extra days [4]. It should be noted that the functional indicators identified as being associated with loss of independence have also been found to be also associated with prolonged hospital stays [4], defined in relation to the T2A upper threshold. The main explicative factor, according to this work, is the lack of downstream rehabilitation and follow-up care, since physiotherapy for walking difficulties, and increased risk of fall subsequent to a long period in bed arising from the acute pathology, increase the length of stay all the more when it is short-stay facilities that are involved [4].

As well as early rehabilitation and mobilization, early attention for nutrition and prescription of nutritional supplements might be a great benefit in elderly hospitalized patients. The evidence for this benefit seems to be limited in the literature [46-48]. Authors' conclusions of recent reviews and meta-analysis about oral protein and energy supplementation are that supplementation appears to produce a small but consistent weight gains. However, the evidence of a benefit to functional outcomes is little. In the literature, too few data are reported and the time scale of most studies was too short to have realistic chance to detecting differences in morbidity, functional status and quality of life [46]. Furthermore, most trials do not address the organizational and practical challenges faced by practitioners trying to meet the individual needs and preferences of those at risk from malnutrition [46, 47]. In summary, if oral protein and energy supplements can improve nutritional status for undernourished elderly patients, additional data from large-scale multicentre trials are still required to evaluate the benefit to functional outcomes [46-48].

The confidence intervals for the ORs calculated for the various factors identified are very wide. This shows a certain lack of statistical power in the estimation of the relationships observed. Nevertheless the significance of the statistical tests comparing ORs to the value 1 shows that the relationships observed do exist. According to the data provided by the calculation of Spearman's $r$ coefficients, the degree of multicollinearity among the various variables selected cannot explain the CI95\% range, which thus does not reflect any instability of the statistical model used.

\section{Conclusion}

This study shows that if generally recognised frailty parameters are taken into account [1, 49], a set of simple items enables a predictive approach to loss of independence subsequent to emergency hospitalization. Thus a diagnosis of lack of autonomy, walking difficulties, fall risk and/or malnutrition at the start of hospitalization can provide a predictive approach for loss of independence. But beyond consideration of the elaboration of preventive policies targeting the risk population identified by these markers, the results presented in the present study suggest 
the imperative need to adapt the geriatric care offer, and in particular the follow-up and rehabilitation care offer. In addition, the identification of functional indicators as early markers for loss of independence should provide incentive for removing the sector-type organization patterns observed in France that partition acute care and rehabilitation departments, for which the justification is purely administrative. The creation of a single care sector would greatly facilitate the early rehabilitation care required for the elderly, while at the same time ensuring adequate care for the pathologies that initially led to the hospitalization.

\section{References}

1. Fried LP, Ferrucci L, Darer J, et al. Untangling the concepts of disability, frailty, and comorbidity: implications for improved targeting care. J Gerontol A Biol Sci Med 2004;59:M255-63.

2. Katz S. Assessing self-maintenance. Activities of daily-living, mobility and instrumental activities of daily-living. J Am Geriatr Soc 1983;31:721-7.

3. National Institutes of Health Consensus Development Conference Statement: Geriatrics assessment methods for clinical decisionmaking. J Am Geriatr Soc 1988;36:342-7.

4. Lang PO, Heitz Damien, Hédelin G, et al. Early markers of prolonged hospital stays in older people: a prospective, multicenter study of 908 inpatients in French acute hospitals. J Am Geriatr Soc 2006;54:1031-9.

5. Wu AW, Yasui Y, Alzola C, et al. Predicting functional status outcomes in hospitalized patients aged 80 years and older. J Am Geriatr Soc 2000;48:6-15.

6. Sager MA, Franke T, Inouye SK, et al. Functional outcomes of acute medical illness and hospitalization older persons. Arch Intern Med 1996;156:645-52.

7. Landefeld CS, Palmer RM, Kresevic DM, et al. A randomized trial of care in a hospital medical unit especially designed to improve the functional outcomes of acutely ill older patients. $\mathrm{N}$ Eng J Med 1995;332:1338-44.

8. Landefeld CS, Palmer RM, Kresevic DM, et al. A randomized trial of care in a hospital medical unit especially designed to improve the functional outcomes of acutely ill older patients. N Eng J Med 1995;332:1338-44.

9. Creditor MC. Hazards of hospitalization in the elderly. Ann Intern Med 1993;118:219-23.

10. Hirsch $\mathrm{CH}$, Sommers L, Olsen A. The natural history of functional morbidity in hospitalized older patients. J Am Geriatr Soc 1990;38:1296-303.

11. Gillick MR, Serell NA, Gillick LS. Adverse consequences of hospitalization in the elderly. Soc Sci Med 1982;16:1033-8.

12. Covinsky KE, Palmer RM, Fortinsky RH, et al. Loss of independence in activities of daily living in older adults hospitalized with medical illness: increased vulnerability with age. J Am Geriatr Soc 2003;51:451-8.

13. Brach JS, VanSwearingen JM. Physical impairment and disability: relationship to performance of activities of daily living in community-dwelling odler men. Phys Ther 2002;82:752-61.

14. Imbert F, Lang PO, Meyer N, et al. Description des conditions de vie de la population âgée de 75 ans ou plus vivant à domicile en Alsace. Rev Epidémiol Sante Publique 2005;53:153-65.

15. Nybo H, Gaist D, Jeune B, et al. Functional status and self-rated health in 2,262 nonagerians: the Danish 1905 cohort survey. J Am Geriatr Soc 2001;49:601-9.
16. Fillenbaum GC. Functional ability. In: Ebrahim S, Kalache A, editors. Epidemiology in old age. London: BMJ Publishing Group; 1996.p. 228-235.

17. Gilleard CJ, Willmott M, Viddadi KS. Self-report measures of mood and morale in elderly depressive. $\mathrm{Br} \mathrm{J}$ Psychiat 1981;138:230-5.

18. Gilleard CJ, Willmott M, Viddadi KS. Self-report measures of mood and morale in elderly depressive. $\mathrm{Br} \mathrm{J}$ Psychiat 1981;138:230-5.

19. Folstein MF, Folstein SE, McHugh PR. 'Mini-mental state'. A practical method for grading the cognitive state of patients for the clinician. J Psychiatr Res 1975;12:189-98.

20. Folstein MF, Folstein SE, McHugh PR. 'Mini-mental state'. A practical method for grading the cognitive state of patients for the clinician. J Psychiatr Res 1975;12:189-98.

21. Podsialdo D, Richardson S. The timed "Get up \& Go": a test for basic functional mobility for frail elderly persons. J Am Geriatr Soc 1991;39:142-8.

22. Vellas B, Wayne SJ, Baumgartner RN, et al. One-leg-balance is an important predictor of injurious falls in older persons. J Am Geriatr Soc 1997;45:735-8.

23. Sundararajan V, Henderson T, Perry C, et al. New ICD-10 version of the Charlson Comorbidity Index predicted in-hospital mortality. J Clin Epidemiol 2004;57:1288-94.

24. Buntinx F, Niclaes L, Suetens C, et al. Evaluation of Charlson's comorbidity index in elderly living in nursing homes. J Clin Epidemiol 2002;55:1144-7.

25. Norton D, Mclaren R, Exton-Smith AN. An Investigation of Nursing Problems in Hospitals. New York: Churchill Livingstone, 1975.

26. Pakerson GR, Broahead WE, Tse CKJ. The Duke Health Profile. A 17-item measure of health and dysfunction. Med Care 1990;28:1056-72.

27. Zarit SH, Reever KE, Bach-Peterson J. Relatives of impaired elderly: Correlates of feelings of burden. Gerontologist 1980;20:649-55.

28. Armitage P, Berry G, Matthews JNS. Statistical Methods in Medical research: Oxford, England: Blackwell Scientific, 2002.

29. Hosner DW, Lemeshow S. Applied logistic regression. NewYork: John Wiley \& Sons; 1989.

30. Stuck AE, Egger M, Beck JC. A controlled trial of geriatric evaluation. N Eng J Med 2002;347:371-3.

31. Stuck AE, Egger M, Beck JC. A controlled trial of geriatric evaluation. N Eng J Med 2002;347:371-3.

32. Stiggelbout AM, Molewijk AC, Otten W, et al. Ideals of patient autonomy in clinical decision making: a study on the development of a scale to assess patients' and physicians' views. J Med Ethics 2004:30:268-74.

33. Hirvensalo M, Rantanen T, Heikkinen E. Mobility difficulties and physical activity as predictor of mortality and loss independence in the community-living older population. J Am Geriatr Soc 2000;48:493-8.

34. Jeandel C, Pfitzenmeyer P, Vigouroux P. Un programme pour la gériatrie : 5 objectifs, 20 recommandations, 45 mesures pour atténuer l'impact du choc démographique sur le fonctionnement des hôpitaux dans les 15 ans à venir. Paris: Ministère de la sécurité sociale, des personnes âgées, des personnes handicapées et de la famille, République Française., 2006.

35. Landi F, Onder G, Cesari M, et al. Psychotropic medications and risk for falls among community-dwelling frail older people: an observational study. J Gerontol A Biol Sci Med 2005; 60:622-6.

36. Blain H, Blain A, Trechot $\mathrm{P}$, Jeandel C. The role of drugs in fall in the elderly. Epidemiologic aspects. Presse Med 2000;29:67380 . 
37. Blain H, Blain A, Trechot $P$, Jeandel C. The role of drugs in fall in the elderly. Epidemiologic aspects. Presse Med 2000;29:67380.

38. Fromage B. Self concept in falling and non-falling elderly. Encephale 2005;31:601-8.

39. Covinsky KE, Wu AW, Landefeld CS. Health status vs Quality of Life in older patients: does the distinction matter? Am J Med 1999;106:435-40.

40. Belmin J. Assessing nutritional status in elderly: a different approach from assessing general health status. Press Med 2000;29:2169-70.

41. Kyle UG, Genton L, Pichard C. Hospital length of stay and nutritional status. Curr Opin Clin Nutr Metab Care 2005;8:397402.

42. Fillol C, Ittah-Desmeulles H, Bourdillon F, et al. Durée de séjour et orientation des personnes hospitalisées âgées de 80 ans et plus dans un CHU parisien. Rev de Gériatrie 2006;31:405-13.

43. Fanello S, Moutel L, Houssin L, Durant-Stocco, Roy PM. Analysis of the management of patients aged 75 and older in admitting en emergency service of a large hospital. Santé Publique 1999;11:465-82.

44. Vetel JM, Lussier MD, Clément JP, et al. Commentaires à propos de la tarification à l'activité en court séjour gériatrique. Rev de Gériatrie 2005;30:238-40.

45. Saint-Jean O, Lahjibi-Paullet H, Somme D. Tarification à l'activité et court séjour gériatrique. Rev de Gériatrie 2004;29:687-92.

46. Milne AC, Potter J, Avenell A. Protein and energy supplementation in elderly people at risk from undernutrition. Cochrane Database Syst Rev 2005;2:CD003288.

47. Milne AC, Avenell A, Potter J. Meta-analysis: protein and energy supplementation in older people. Ann Intern Med 2006;144:3748.

48. Avenell A, Handoll HH. Nutritional supplementation for hip fracture aftercare in older people. Cochrane Database Syst Rev 2006;4:CD001880.

49. Rockwood K. Frailty and its definition: a worthy challenge. J Am Geriatr Soc 2005;53:1069-1070. 